\title{
The condition requiremens for optical bistability in semiconductor laser under injection locking
}

M. S. Mohammed

Musabsalh_67@yahoo.com
A. I. Abdullah

Ghaa4@yahoo.com

Department of Physics, College of Education

University of Mosul

Mosul - IRAQ

Received

r. / $12 / 2003$
Accepted

$24 / 10 / 2005$

\section{Abstract}

The experimental fulfillment for optical bistability in a semiconductor laser under injection locking is studied. The required setup to provide the stability in current, temperature and power output of the laser diode used in experiments has been described in detail. A small change in the injection power of the slave laser SL could induce a dynamic change of the lasing power of the master laser ML has been observed. Optical bistability for two non identical laser was possible has been experimentally observed.

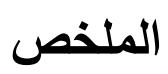

تم في هذا البحث دراسة الثروط التجريبية للتشغيل ثائي الاستقرارية البصري في الليزر

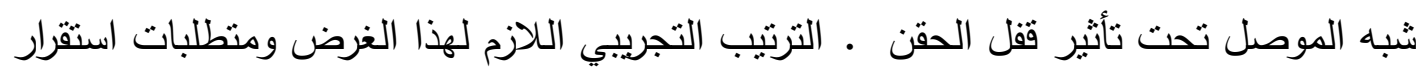

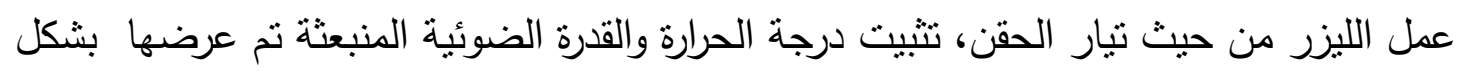

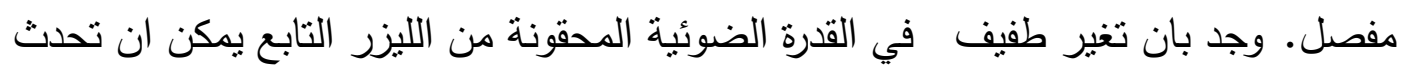

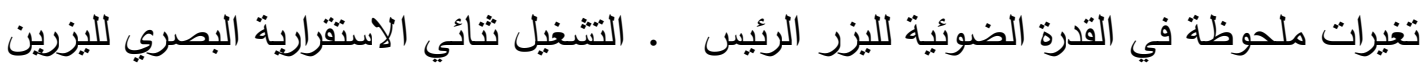
غير منماتلين نم ملاحظته تجريبياً. 
The condition requiremens for optical bistability in semiconductor ... 
The condition requiremens for optical bistability in semiconductor ... 
The condition requiremens for optical bistability in semiconductor ... 
The condition requiremens for optical bistability in semiconductor ... 
The condition requiremens for optical bistability in semiconductor ... 
The condition requiremens for optical bistability in semiconductor ... 